\title{
DESAFIOS DA PERMANÊNCIA ESTUDANTIL UNIVERSITÁRIA: UM ESTUDO SOBRE A TRAJETÓRIA DE ESTUDANTES ATENDIDOS POR PROGRAMAS DE ASSISTÊNCIA ESTUDANTIL
}

\author{
ELIANA ALMEIDA SOARES GANAM ${ }^{1}$ \\ ORCID: https://orcid.org/0000-0003-4390-5822 \\ ANA KEILA MOSCA PINEZI ${ }^{2}$ \\ ORCID: https://orcid.org/0000-0001-9190-7246
}

\begin{abstract}
RESUMO: O presente artigo discute a permanência estudantil no ensino superior público brasileiro a partir de um estudo realizado na Universidade Federal de São Paulo. No estudo realizado, buscou-se compreender como um grupo de estudantes universitários atendidos por programas de assistência estudantil constrói sua trajetória acadêmica, considerando a origem socioeconômica assimétrica. Foi analisada, neste artigo, parte dos dados de entrevistas em profundidade realizadas nesta pesquisa. Observa-se que a trajetória de estudantes provenientes de classes sociais diferentes das que tradicionalmente ocuparam a universidade pública convive com contradições que tornam sua permanência na universidade um desafio constante. Elementos do mundo material, ligados à subsistência financeira, e simbólicos, ligados à percepção de pertencimento, indicam que a passagem pela universidade pública não garante, em si, mudanças na forma como esses estudantes são percebidos a partir do "lugar" social, embora essas percepções não impeçam que estudantes ultrapassem as barreiras simbólicas de discriminação e exclusão e busquem formas de equiparação à condição standart do estudante universitário.
\end{abstract}

Palavras-chave: permanência estudantil, assistência estudantil, universidade pública.

\section{CHALLENGES OF UNIVERSITY STUDENT PERMANENCE: A STUDY ABOUT THE TRAJECTORY OF STUDENTS ASSISTED BY STUDENT ASSISTANCE PROGRAMS}

\begin{abstract}
This article discusses student permanence in Brazilian public higher education based on a study conducted at the Federal University of São Paulo. In the study, we sought to understand how a group of college students assisted by student assistance programs build their academic trajectory, considering their asymmetric socioeconomic background. This article analyzes part of the data from the in-depth interviews carried out in this research. It can be observed that the trajectory of students coming

\footnotetext{
1 Tribunal de Justiça de São Paulo (TJSP). Limeira, SP, Brasil. < eliana.nae@gmail.com>

${ }^{2}$ Departamento de Saúde Coletiva (DeSCo) - Universidade Federal do Triângulo Mineiro (UFTM). Uberaba, MG, Brasil.

$<$ keipinezi@gmail.com>
} 
from social classes different from those that traditionally occupied the public university coexists with contradictions that make their permanence in the university a constant challenge. Elements of the material world, linked to financial subsistence, and symbolic, linked to the perception of belonging, indicate that the passage through the public university does not guarantee, in itself, changes in the way these students are perceived from the social "place", although these perceptions do not prevent students from overcoming the symbolic barriers of discrimination and exclusion and seeking ways to equalize the standard condition of the university student.

Keywords: student permanence, student assistance, public university.

\section{DESAFÍOS DE LA PERMANENCIA ESCOLAR: TRAYECTORIA DE LOS ESTUDIANTES ATENDIDOS EN LOS PROGRAMAS DE ASISTENCIA UNIVERSITÁRIA}

RESÚMEN: El artículo analiza la permanencia de los estudiantes en la educación superior pública brasileña de un estudio realizado en la Universidad Federal de São Paulo. En el estúdio, buscamos comprender cómo un grupo de estudiantes universitarios asistidos por programas de asistencia estudiantil construyen su trayectoria académica, considerando el origen socioeconómico assimétrico. En este artículo se analizó parte de los datos de las entrevistas en profundidad realizadas en esta investigación. Se observa que la trayectoria de estudiantes de diferentes clases sociales que aquellos que tradicionalmente ocuparon la universidad pública coexiste con contradicciones que hacen la permanencia en la universidad sea un desafío constante. Elementos del mundo material, vinculados a la subsistencia financiera, y simbólicos, vinculados a la percepción de pertenencia, indican que el paso por la universidad pública no garantiza cambios en la forma en que estos estudiantes son percibidos desde el "lugar" social. Sin embargo, estas percepciones no impiden que los estudiantes superen las barreras simbólicas de discriminación y exclusión y busquen formas de equipararse con la condición padrón del estudiante universitario.

Palabras clave: permanencia estudantil, asistencia estudiantil, universidad pública. 


\section{INTRODUÇÃO}

A Política de Educação Superior pública no Brasil constituiu-se, tradicionalmente, de modo elitista e insuficiente frente à exigência de vagas e à necessidade de qualificação profissional da população, além de ter-se desenvolvido em um processo descontínuo. Segundo Almeida (2017, p. 6), historicamente "a extensão da escolaridade foi marcada por improvisos e precariedade, oferta insuficiente de vagas, baixo rendimento educacional dos que conseguiram frequentar a escola e restrições ao acesso de acordo com o pertencimento de classe social do indivíduo”. Entretanto, nas últimas décadas, a partir de 2003, um movimento de contrarreforma da educação foi proposto com a finalidade de contraposição a esse processo histórico, conjugando estratégias políticas no campo da educação superior no Brasil, que podem ser observadas pelos seguintes elementos: expansão das universidades públicas no País, ampliação de oportunidades e vagas, mudanças nos processos de avaliação e seleção para ingresso na universidade pública e aporte financeiro para a manutenção de estudantes com trajetórias de vulnerabilidade social na universidade.

Tais estratégias foram concretizadas na última década, principalmente no período de 2007 a 2012, a partir do aumento dos investimentos em políticas públicas ligadas à expansão de vagas nas instituições federais de ensino superior materializadas no Programa de Apoio a Planos de Reestruturação e Expansão das Universidades Federais, conhecido como REUNI, instituído em 2007 pelo Decreto Presidencial $\mathrm{n}^{\circ}$. 6.096. Esse programa teve como proposta central pôr em prática políticas de democratização do acesso e da inclusão social no ensino superior, garantindo, destarte, a diversificação do público universitário e possibilitando a maior presença de estudantes oriundos das camadas populares.

Nesse programa foi fixado, para as universidades públicas federais, um contrato de gestão com metas de desempenho para o recebimento de investimentos financeiros. Tais proposições tinham como finalidade a criação de condições para a ampliação do acesso e da permanência no ensino superior público federal, cujas diretrizes e metas previam, entre outras questões, a redução da evasão e a retenção, além da ocupação de vagas ociosas e a ampliação de políticas de inclusão e assistência estudantil, de modo a promover a elevação gradual das taxas de conclusão de cursos de graduação.

Se a avaliação dos impactos da proposta é uma tarefa histórica do porvir, compreendendo os desdobramentos concretos nos termos de inserção social e danova requalificação proporcionadas pelauniversidade pública, alguns elementos podem ser compreendidos dentro do espectro de incidentes nesse processo. É sobre elementos deste processo que este trabalho se debruça, com focona elaboração particular e coletiva sobre eles que envolve, portanto, significados sociais e sentidos pessoais e como esta elaboração é indicativa de mecanismos que podem ajudar a refletir e a compreender a condição social na qual esses estudantes estão inseridos.

Este artigo expõe parte dos resultados de uma pesquisa sobre a permanência de estudantes das camadas populares na universidade pública brasileira. O objetivo especifico foi compreender como estudantes oriundos dessas camadas construíram a sua trajetória universitária. Essa trajetória é construída a partir da perspectiva dos sentidos e dos significados atribuídos por estudantes atendidos pelos programas de Assistência Estudantil na Universidade Federal de São Paulo (UNIFESP).

Esses processos sociais foram examinados a partir de uma pesquisa qualitativa que compreendeu uma aproximação sucessiva das questões que envolvem a permanência estudantil no ensino superior. Essa aproximação foi empreendida empiricamente pela observação de estudantes realizada nos espaços da universidade e por meio de entrevistas individuais com um grupo de 15 estudantes atendidos pelos programas de Assistência Estudantil da UNIFESP. Para se ter acesso a informações com a qualidade específica que se pretendia, ou seja, depurada a partir de uma trajetória já percorrida - e, portanto, com mais elementos vivenciados -, optou-se pela realização das entrevistas junto aos estudantes matriculados no último ano dos sete ${ }^{3}$ cursos de graduação existentes no campus Baixada Santista da Universidade Federal de São Paulo e atendidos pelos programas de Assistência Estudantil. As entrevistas foram realizadas entre julho de 2015 e março de 2016. Já a observação, pensada

\footnotetext{
${ }^{3}$ Os cursos oferecidos são: Educação Física, Fisioterapia, Nutrição, Psicologia, Terapia Ocupacional, Serviço Social, Bacharel Interdisciplinar em Ciência e Tecnologia com ênfase em Ciências do Mar (BICTMAR). Os cinco primeiros são oferecidos em período integral, e os demais, com turmas no período vespertino e noturno.
} 
de forma contínua e sistemática, foi realizada em sala de aula no período de abril a novembro de 2015. Intentou-se, destarte, a construção de um panorama baseado na experiência de permanência na universidade e nas relações com a política de assistência estudantil constituída a partir da autopercepção e da autodeclaração desses participantes.

Essa escolha foi motivada pela ideia de que esses estudantes já teriam condições de avaliar seu percurso acadêmico por meio das várias dimensões que constituíram sua trajetória e atribuir com maior clareza os significados ao processo de formação, bem como ao papel da política de Assistência Estudantil no percurso da sua graduação. Isso poderia contribuir para as discussões relacionadas ao percurso acadêmico, com suas variações e singularidades vivenciadas ao longo dos anos de graduação, o que, como se pôde verificar, de fato aconteceu.

Todos os participantes eram solteiros e originários do estado de São Paulo; destes, 73\% cursaram integralmente o Ensino Médio em instituições públicas de ensino e apenas uma( tinha filhos. A totalidade dos participantes da pesquisa compõe a primeira geração familiar a ter acesso ao ensino superior. À época, embora nenhum deles exercesse atividade remunerada regular, 77\% apresentavam histórico de atividade laborativa anterior ao ingresso na universidade e $60 \%$ se autodeclararam pretos ou pardos. No que se refere à forma de ingresso na universidade, $80 \%$ não ingressaram por sistema de reserva de vagas, leia-se cotas ${ }^{4}$. Vale ressaltar que a maioria ingressou na universidade na faixa etária esperada (NIEROTKA; TREVISOL, 2019), ou seja, entre 18 e 24 anos, o que significa dizer que o grupo não apresenta um ingresso tardio no ensino superior.

\begin{tabular}{|c|c|c|c|c|c|c|c|}
\hline $\begin{array}{l}\text { Identifi } \\
\text { cação }\end{array}$ & Gênero & Idade & $\begin{array}{l}\text { Cor da } \\
\text { pele }\end{array}$ & $\begin{array}{l}\text { Procedência } \\
\text { Geográfica }\end{array}$ & Curso & $\begin{array}{l}\text { Forma de } \\
\text { ingresso na } \\
\text { UNIFESP }\end{array}$ & $\begin{array}{l}\text { Ensino } \\
\text { Médio }\end{array}$ \\
\hline E1 & Feminino & $\begin{array}{c}50 \\
\text { anos }\end{array}$ & Branca & $\begin{array}{l}\text { Baixada } \\
\text { Santista }\end{array}$ & $\begin{array}{c}\text { Serviço } \\
\text { Social } \\
\text { Noturno }\end{array}$ & $\begin{array}{c}\text { Ampla } \\
\text { concorrência }\end{array}$ & $\begin{array}{l}\text { Escola } \\
\text { Pública }\end{array}$ \\
\hline E2 & Feminino & $\begin{array}{c}26 \\
\text { anos }\end{array}$ & Preta & $\begin{array}{l}\text { Baixada } \\
\text { Santista }\end{array}$ & $\begin{array}{c}\text { Terapia } \\
\text { Ocupacional }\end{array}$ & $\begin{array}{c}\text { Ampla } \\
\text { concorrência }\end{array}$ & $\begin{array}{l}\text { Escola } \\
\text { Pública }\end{array}$ \\
\hline E3 & Feminino & $\begin{array}{c}23 \\
\text { anos }\end{array}$ & Parda & $\begin{array}{c}\text { Região } \\
\text { Metropolitana }\end{array}$ & Psicologia & $\begin{array}{c}\text { Ampla } \\
\text { concorrência }\end{array}$ & $\begin{array}{l}\text { Escola } \\
\text { Pública }\end{array}$ \\
\hline E4 & Feminino & $\begin{array}{c}22 \\
\text { anos }\end{array}$ & Branca & $\begin{array}{c}\text { Interior de São } \\
\text { Paulo }\end{array}$ & $\begin{array}{c}\text { Serviço } \\
\text { Social } \\
\text { Vespertino }\end{array}$ & $\begin{array}{c}\text { Ampla } \\
\text { concorrência }\end{array}$ & $\begin{array}{l}\text { Escola } \\
\text { Privada com } \\
\text { bolsa parcial }\end{array}$ \\
\hline E5 & Feminino & $\begin{array}{c}23 \\
\text { anos }\end{array}$ & Branca & $\begin{array}{c}\text { Interior de São } \\
\text { Paulo }\end{array}$ & Psicologia & $\begin{array}{c}\text { Ampla } \\
\text { concorrência }\end{array}$ & $\begin{array}{c}\text { Escola } \\
\text { Filantrópica }\end{array}$ \\
\hline E6 & Feminino & $\begin{array}{c}24 \\
\text { anos }\end{array}$ & Branca & $\begin{array}{c}\text { Região } \\
\text { Metropolitana }\end{array}$ & Nutrição & Cotista & $\begin{array}{l}\text { Escola } \\
\text { Pública }\end{array}$ \\
\hline E7 & Feminino & $\begin{array}{c}23 \\
\text { anos }\end{array}$ & Preta & $\begin{array}{c}\text { Interior de São } \\
\text { Paulo }\end{array}$ & Nutrição & Cotista & $\begin{array}{l}\text { Escola } \\
\text { Pública }\end{array}$ \\
\hline
\end{tabular}

\footnotetext{
${ }^{4} \mathrm{Na}$ época do ingresso desses estudantes na UNIFESP (2011-2012), a instituição havia implementado um programa de reserva de vagas (Resolução 23/2004), na condição de ação afirmativa. A oferta de vagas nos cursos de graduação foi ampliada em 10\%, e essas vagas seriam destinadas aos estudantes que tivessem cursado o ensino médio integralmente em escola pública e aos autodeclarados pretos, pardos ou indígenas.
} 


\begin{tabular}{|c|c|c|c|c|c|c|c|}
\hline $\mathrm{E} 8$ & Feminino & $\begin{array}{c}24 \\
\text { anos }\end{array}$ & Preta & $\begin{array}{l}\text { Baixada } \\
\text { Santista }\end{array}$ & $\begin{array}{c}\text { Ciências do } \\
\text { Mar } \\
\text { Vespertino }\end{array}$ & $\begin{array}{c}\text { Ampla } \\
\text { concorrência }\end{array}$ & $\begin{array}{l}\text { Escola } \\
\text { Pública }\end{array}$ \\
\hline E9 & Masculino & $\begin{array}{c}22 \\
\text { anos }\end{array}$ & Branca & $\begin{array}{c}\text { Interior de São } \\
\text { Paulo }\end{array}$ & Nutrição & $\begin{array}{c}\text { Ampla } \\
\text { concorrência }\end{array}$ & $\begin{array}{l}\text { Escola } \\
\text { Pública }\end{array}$ \\
\hline E10 & Feminino & $\begin{array}{c}25 \\
\text { anos }\end{array}$ & Branca & $\begin{array}{c}\text { Interior de São } \\
\text { Paulo }\end{array}$ & $\begin{array}{l}\text { Ciências do } \\
\text { Mar Noturno }\end{array}$ & $\begin{array}{c}\text { Ampla } \\
\text { concorrência }\end{array}$ & $\begin{array}{l}\text { Escola } \\
\text { Pública }\end{array}$ \\
\hline E11 & Feminino & $\begin{array}{c}24 \\
\text { anos }\end{array}$ & Parda & $\begin{array}{l}\text { Baixada } \\
\text { Santista }\end{array}$ & $\begin{array}{l}\text { Ciências do } \\
\text { Mar Noturno }\end{array}$ & Cotista & $\begin{array}{l}\text { Escola } \\
\text { Pública }\end{array}$ \\
\hline E12 & Feminino & $\begin{array}{c}25 \\
\text { anos }\end{array}$ & Parda & $\begin{array}{c}\text { Interior de São } \\
\text { Paulo }\end{array}$ & Fisioterapia & $\begin{array}{c}\text { Ampla } \\
\text { concorrência }\end{array}$ & $\begin{array}{l}\text { Escola } \\
\text { pública }\end{array}$ \\
\hline E13 & Masculino & $\begin{array}{c}26 \\
\text { anos }\end{array}$ & Parda & $\begin{array}{c}\text { Região } \\
\text { Metropolitana }\end{array}$ & $\begin{array}{c}\text { Educação } \\
\text { Física }\end{array}$ & $\begin{array}{c}\text { Ampla } \\
\text { concorrência }\end{array}$ & $\begin{array}{l}\text { Escola } \\
\text { Pública }\end{array}$ \\
\hline E14 & Masculino & $\begin{array}{c}23 \\
\text { anos }\end{array}$ & Parda & $\begin{array}{l}\text { Baixada } \\
\text { Santista }\end{array}$ & $\begin{array}{l}\text { Educação } \\
\text { Física }\end{array}$ & $\begin{array}{c}\text { Ampla } \\
\text { concorrência }\end{array}$ & $\begin{array}{c}\text { Escola } \\
\text { Privada com } \\
\text { bolsa } \\
\text { Integral }\end{array}$ \\
\hline E15 & Feminino & $\begin{array}{c}23 \\
\text { anos }\end{array}$ & Preta & $\begin{array}{l}\text { Capital do } \\
\text { estado }\end{array}$ & $\begin{array}{c}\text { Serviço } \\
\text { Social } \\
\text { Vespertino }\end{array}$ & $\begin{array}{c}\text { Transferência } \\
\text { Externa }\end{array}$ & $\begin{array}{l}\text { Escola } \\
\text { Privada com } \\
\text { bolsa parcial }\end{array}$ \\
\hline
\end{tabular}

Fonte: Elaboração própria.

Neste texto, nossa análise está focada em parte das entrevistas realizadas com os estudantes apresentados no quadro acima.

Para a obtenção do material empírico, construiu-se um levantamento de sentidos e significados atribuídos à trajetória acadêmica por uma parte de estudantes assistidos, sob a mediação da política de Assistência Estudantil, o que permitiu o acesso às questões materiais e simbólicas dessa inserção e permanência estudantil, possibilitando uma leitura acerca dos limites e das potencialidades da construção formal da política de assistência estudantil a partir da visão desses mesmos estudantes. As narrativas presentes no discurso dos entrevistados permitiram a abordagem de dimensões que habitualmente não são suscitadas a partir de dados quantitativos.

É possível dizer que se trata de um grupo de estudantes que foge ao padrão tradicional dos denominados herdeiros (BOURDIEU; PASSERON, 2014), grupo social para o qual o ingresso na universidade constitui um habitus, no qual a temática da universidade acompanha a rotina familiar e escolar, assim como a relação que mantêm com o saber e os produtos escolares. Aqueles representam segmentos sociais que, até recentemente, pouco circulavam no ambiente universitário. Conforme pontua Teixeira (2011, p. 46), "chegar ao ensino superior em nada se configura como algo 'natural' para esse grupo, diferentemente do que se observa nas classes médias e intelectualizadas".

À vista disso, o ingresso no ensino superior demonstra uma variação de trajetória desse grupo, de modo que os coloca em uma posição social diferente em relação aos seus pais e familiares. Entretanto, há que se ressaltar, ainda segundo Bourdieu (2007), que a universidade é um espaço onde ainda persiste e é possível visualizar a desigualdade e a segmentação sociais, uma vez que se legitimam as diferenças socioculturais entre os grupos. Essa é a diferenciação ou recurso social que Bourdieu (2007) intitulou "capital cultural", fonte de distinção e privilégio entre segmentos sociais, baseada numa cultura familiar e escolar distintivas.

Lembramos que, segundo Bourdieu, o sistema escolar é "um dos fatores mais eficazes de conservação social, pois fornece a aparência de legitimidade às desigualdades sociais, e sanciona a herança cultural e o dom social tratado como um dom natural” (BOURDIEU, 2007, p. 41). A ideologia do mérito pessoal, nesse contexto, busca justificar pelo suposto empenho ou qualidades individuais a contradição entre os que alcançam êxito e os que fracassam e, por conseguinte, escamotear "os mecanismos de eliminação que agem durante todo o cursus" (BOURDIEU, 2007, p. 41), as razões reais das desigualdades sociais também no interior das universidades. 


\section{TRAJETÓRIA E VIVÊNCIAS UNIVERSITÁRIAS}

Para a análise das entrevistas, optou-se pela apresentação em eixos articulados que permitissem o exame e a interpretação das narrativas e dos relatos de modo que pudessem reconstruir a trajetória universitária dos estudantes em questão. Um segundo nível de análise, que também incide na forma como foi proposta a compreensão desses processos, está ligado às observações realizadas junto aos estudantes no espaço universitário. Os estudantes, em entrevista, reconstruíram suas experiências como universitários e retomaram grande parte das situações que envolveram e envolvem a permanência na universidade. Por outro lado, alguns elementos da convivência estudantil, que não passam pelo crivo do discurso do estudante, também puderam ser identificados pelas observações. Juntos, os dois níveis de levantamento de dados proporcionaram condições analíticas que permitiram a constituição de dois eixos de análise, a saber: 1) permanência material; e 2) permanência simbólica.

Sabe-se que a discussão do acesso/ingresso à universidade, principalmente à universidade pública, está intrinsecamente vinculada à questão da permanência estudantil, sobretudo em um contexto de diversificação do perfil dos estudantes promovido pelo programa de expansão das Instituições Federais de Ensino Superior. Assim sendo, a categoria permanência permeou todo este trabalho e, por conseguinte, apresenta-se como eixo principal e indispensável da análise e será o foco da discussão a ser apresentada. Apesar da inter-relação entre ingresso e permanência, enfatiza-se que a discussão, neste artigo, se dará em torno da permanência estudantil e não do ingresso.

A permanência estudantil, conforme ressalta Santos (2009) em seu estudo sobre a trajetória de estudantes negros na Universidade Federal da Bahia, apresenta duas dimensões inter-relacionadas, a saber: uma definida como material e outra como simbólica, porém ambas envolvem formas imbricadas de existência dos estudantes no interior da universidade. Para fins elucidativos, chamou-se de Permanência Material a que envolve a produção da vida material e Permanência Simbólica a que abrange as condições simbólicas, as representações sociais, de modo a coadunar com a perspectiva apresentada por Santos (2009).

\section{A permanência material}

À primeira vista, é a condição financeira o primeiro e determinante entrave que se evidencia aos estudantes das camadas populares para o desenvolvimento de seu curso de graduação, tendo sido o mais citado e problematizado nas entrevistas e nos momentos de observações. A sobrevivência concreta cotidiana e a forma de viabilizá-la objetivamente perpassa toda a trajetória acadêmica desses estudantes e, por vezes, pode retirar do(a) estudante a concentração necessária para dar resposta aos estudos. Segundo Portes (2006, p. 227), é possível dizer que:

Se a condição econômica não é determinante das ações e práticas do estudante pobre - em um passado e em um presente -, ela é um componente real, atuante, mobilizador de sentimentos que comumente produzem sofrimento neste tipo de estudante e ameaçam sua permanência na instituição.

Para atendimento das necessidades materiais, foi criado institucionalmente um programa de assistência estudantil como uma das estratégias e suporte para a manutenção desses estudantes no espaço universitário.

Vale ressaltar que, tradicionalmente, a UNIFESP não dispunha de serviços e/ou programas regulares voltados à questão da assistência estudantil anteriores à consolidação do seu projeto de expansão universitária em 2010. A assistência estudantil trata-se de uma preocupação recente no âmbito institucional, diferentemente do que se observa na maioria das Instituições Federais de Ensino (IFES). Ela concretiza-se com base no Programa Nacional de Assistência Estudantil (PNAES), datado de 2008, que designa recursos específicos para que todas as IFES subsidiem programas locais de permanência/assistência estudantil. 
Esse programa constitui-se como mecanismo principal para a operacionalização da política de assistência estudantil da UNIFESP e visa criar condições de permanência e aproveitamento pleno da formação acadêmica aos estudantes em situação de vulnerabilidade socioeconômica, sendo destinado a todos(as) os(as) estudantes matriculados(as) nos diversos cursos de graduação de todos os campi da UNIFESP que se apresentam em tal situação.

Ao longo dos últimos anos, os critérios de elegibilidade para inclusão no programa de Assistência Estudantil foram sendo aprimorados, e outros indicadores, além da renda, foram sendo incorporados para a construção de perfis de vulnerabilidade a fim de garantir que os auxílios financeiros disponibilizados pelo programa de Assistência Estudantil atendessem às necessidades desses estudantes a partir do princípio de equidade de condições.

A atribuição de auxílios é feita a partir dos graus de vulnerabilidade identificados na população global de estudantes que atendem aos requisitos de renda familiar per capita de até um salário mínimo e meio. Vulnerabilidade socioeconômica é concebida, para fins de concessão de auxílio financeiro, como o conjunto de situações que podem comprometer a permanência do(a) estudante na Unifesp. Tais situações podem abranger ausência ou dificuldade no acesso a bens e serviços públicos básicos e/ou direitos sociais. Os valores de auxílios propostos relativos aos graus de vulnerabilidade identificados têm como referência os seguintes parâmetros: perfil V- R $\$ 160,00$; perfil IV- $\mathrm{R} \$ 213,00$; perfil III- R \$373,00; perfil II- R \$586,00; e perfil I- R $\$ 746,00$.

Tal suporte financeiro estrutura-se como ferramenta crucial para a entrada na vida universitária, para o prosseguimento desta, assim como para o alcance da conclusão do curso escolhido. Nesse quesito, houve um consenso entre todos os entrevistados com relação à importância e ao significado do programa de Assistência Estudantil para a sua permanência material na universidade.

[...] Então, eu tinha um pouco de medo em relação a não conseguir pagar o aluguel, sustentar e tudo mais. Na UNIFESP, eu consegui, assim, tranquilamente com a bolsa, consegui concluir o curso porque se não fosse com os valores da bolsa, eu não teria concluído o curso, porque eu não teria como me manter em Santos. (E6, Estudante de Nutrição, periodo integral, 25 anos).

[...] Porque eu acho que se eu não tivesse o auxílio, eu não ia conseguir fazer a faculdade mesmo morando em Santos. Porque eu não tenho condições mesmo. Se eu entrasse na faculdade e não tivesse bolsa, eu ia literalmente me ferrar todinho. Porque eu ia ter que vir a pé, voltar a pé. Comer, eu não sei nem como eu ia comer na faculdade, porque meu pai ia ter que se desdobrar, a minha mãe também ia ter que se desdobrar. Lógico, pra quem tem dinheiro é fácil, você vir pra outra cidade e o pai banca tudo e a vida segue. Mas, na minha condição, a assistência social, o NAE (Núcleo de Apoio ao Estudante) me ajudou muito, muito, muito, mesmo. (E14, Estudante de Educaşão Física, período integral, 24 anos).

Houve uma fala recorrente entre todos(as) os(as) entrevistados(as) sobre preocupação com a manutenção financeira, o que demonstra a situação de vulnerabilidade social a que estão expostos e a dependência de um programa social que lhes possibilite ocupar espaços sociais dos quais usualmente são excluídos, como é o caso da universidade. Em específico, o programa de Assistência Estudantil tem um estreito vínculo com as necessidades materiais imediatas desses estudantes, uma vez que se constituiu como alternativa para minimização da preocupação cotidiana de garantir o custeio de moradia, alimentação, transporte, da aquisição de material didático e demais despesas básicas de manutenção no espaço universitário. Porém, conforme alerta Portes (2001, p. 177):

Neste caso, não se trata de um viés do olhar do pesquisador ou uma redução de todas as manifestações do universitário pobre pesquisado a uma condição material. É exatamente a satisfação das necessidades básicas que pode liberar esse sujeito para outros empreendimentos constitutivos de uma boa formação escolar, da construção da identidade e da afirmação no mundo, além de assegurar as vantagens escolares que todos eles acumularam em um ambiente hostil a empreendimentos desta natureza.

Como observado, a forma mais imediata e possível de enfrentamento das necessidades materiais por parte desses estudantes foi a busca pela inserção no programa de Assistência estudantil 
oferecido pela instituição; nota-se que o auxílio financeiro institucional já aparecia nas narrativas como plano de subsistência inicial antes mesmo de concretizado o ingresso na universidade.

Se eu não tivesse bolsa, eu num taria... Um dos pontos chave, quando eu descobri a universidade; porque eu descobri a universidade pública e o que ela me traria, que era o auxílio permanência. Tem universidade que tem alojamento. Então eu contava com tudo isso. Até na época do cursinho o pessoal falava: ah, mas você vai pra tão longe, como você vai se manter? Daí, eu: não, eu vou me manter na universidade, ela tem esse benefício. Eles: mas se você não conseguir entrar? Mas eu: não, não tem como não conseguir, eu preciso. Se não tiver, não sei como será. Estava confiante que eu teria esse benefício. (E12, Estudante de Fisioterapia, periodo integral, 25 anos).

Eu fiz muitas pesquisas, vim aqui antes, eu tentei estudar como era essa realidade, mas só por conta de saber que ia ter assistência (estudantil) e eu ia conseguir minimamente ter uma bolsa, porque se não tivesse, seria irreal. Eu ia passar por todo esse processo e ia ficar chupando o dedo em casa, chateada porque eu não ia vir. Porque você não tem como viver, não existe. (E15, Estudante de Serviço Social, periodo vespertino, 23 anos).

Para o grupo de estudantes que dispunha da condição de trabalhador anterior ao ingresso na universidade e, consequentemente, ainda exercia o papel de contribuinte e/ou responsável pelo orçamento doméstico, a preocupação mostrava-se ainda maior. O dilema de conciliar a atividade laborativa que esses estudantes já tinham antes do ingresso na universidade revelou-se como uma questão expressiva e incompatível com a trajetória universitária na maioria dos casos observados, principalmente para os que buscavam cursos de graduação cujas grades curriculares exigem dedicação em período integral.

[...] no meu ensino médio... Segundo e terceiro ano, eu trabalhei. Então, eu trabalhava e estudava de noite. Então, eu ia levando a escola, não reprovei em nenhuma disciplina e nem ano. A gente não estuda como deveria estudar, porque eu ficava cansada, o dia inteiro trabalhando e à noite ia pra escola, então era bem complicado. Então, quando eu vi, que eu vivenciei essa fase da minha vida que era trabalho e estudo, eu falei pra mim: “eu não vou dar conta de ir". Porque universidade é uma coisa muito mais séria, então, eu não vou dar conta. (E6, Estudante de Nutrição, periodo integral, 25 anos).

[...] na época, como eu era a renda da minha casa praticamente, porque eu trabalhava em supermercado, já há seis anos. E tinha um cargo até que alto, então era tudo assim: compra de casa era eu que fazia. As despesas de casa a maioria era comigo. E aí eu tive que conversar com os meus pais. Não tinha como. No começo era muito difícil. (E11, Estudante de Ciências do Mar, periodo noturno, 21 anos).

[...] Eu tinha passado num concurso público e, aí fiquei no dilema: estudo ou trabalho? Estudo ou trabalho? Porque eu precisava ajudar em casa, mas ao mesmo tempo eu precisava estudar. Então, eu tentei durante o primeiro ano segurar as duas coisas. Eu conseguia parar nos finais de semana, mas eu via que não era o suficiente. (E2, Estudante de Terapia Ocupacional, período integral, 26 anos).

Pesquisadora: E dava pra conciliar a jornada de trabalho com o curso?

E2: Não, porque eu sempre chegava atrasada no trabalho. E era na Praia Grande ainda. Que é longe! Meu Deus! Era uma jornada, sair daqui pra ir pra lá. Eu levava duas horas pra chegar. E eu entrava às três da tarde lá pra sair às onze da noite. Só que aqui eu saía quatro horas da tarde, isso quando saía. Tanto que eu peguei DP (dependência/reprovação) por causa disso. Eu peguei DP por frequência. Apesar de eu frequentar as aulas, eu peguei DP por frequência porque eu não assinava as listas de presença. (E2, Estudante de Terapia Ocupacional, período integral, 26 anos).

Nas narrativas acima, estiveram presentes as restrições que a atividade laborativa diária apresentava às pretensões de desenvolvimento acadêmico desses estudantes, o que comprometeria a experiência universitária de forma plena. Tal situação constituiu-se como mais um desafio para esses estudantes. Vale destacar que, no universo considerado dos estudantes trabalhadores entrevistados, a sua totalidade, em algum momento do curso, seja logo no início ou no decorrer da graduação, se viu obrigada 
a decidir entre a manutenção o da atividade laborativa e a permanência na universidade, dada a impossibilidade de conciliar as duas atividades. Abandonar o trabalho, para esses estudantes, significaria tornar a situação familiar ainda mais precária. Por outro lado, nesse momento de definições, destacou-se o papel das famílias dos estudantes ao apoiarem e darem sustentação simbólica para essa tomada de decisão, mesmo que os estudantes em questão exercessem o papel de provedores e/ou contribuintes do orçamento doméstico.

[...] E aí, então, foi uma decisão bem difícil. Meus pais me ajudaram muito. Eles falaram: "você precisa estudar. Então, se você tiver que deixar o trabalho, e a gente tiver que trabalhar em dois empregos pra você estudar, tudo bem! Não tem problema!' Foi o que eu acabei fazendo. Apesar de eu ficar um mês me martirizando. O que eu vou fazer? E agora? Eu preciso trabalhar pra ajudar em casa, estudar também. Não dá pra conciliar as duas coisas. Eu vou ter que escolher um. Ou eu trabalho, ou eu estudo. Mas eles (pais) falaram assim: "estuda! Que a gente se vira pra poder cuidar da casa, das contas e se precisar te ajudar na universidade". Eu acabei deixando o emprego, pedi exoneração. E fiquei só aqui. (E2, Estudante de Terapia Ocupacional, período integral, 26 anos).

Foi possível perceber que, embora não houvesse uma tradição familiar de acesso ao ensino superior, as famílias dos estudantes em questão entendiam a universidade como uma possibilidade para posterior obtenção de melhores oportunidades no mercado de trabalho. Houve a realização de uma estratégia "educógena" (SILVA, 2003), na qual a escolarização ocupava uma parcela significativa das preocupações familiares, com vistas à construção de um projeto de ascensão profissional para os filhos; nesse contexto, a formação universitária é vislumbrada como estratégia de ascensão social. Entendiam que o acesso ao ensino superior conferiria poder econômico e, consequentemente, a renda, que, de um modo geral, tem razão direta com a escolaridade. A educação formal constituiu-se como força motriz para as transformações das condições de vida dessas famílias, como aponta Santos (2009, p. 69):

No caso das famílias menos abastadas, e em geral negras, a universidade representa um grande
feito, já que no seu imaginário ela estava ausente, distante, pouco provável. A entrada de um
membro destas famílias no ensino superior e a sua permanência têm dois sentidos: um sentido
que é individual e o outro que é grupal, uma vez que ser universitário ou universitária significa a
possibilidade de alterações no seu futuro e no meio social em que este indivíduo circula.

A possibilidade de não trabalhar e a não obrigatoriedade de contribuir com o orçamento familiar graças à solidariedade entre os membros da família permitiriam ao estudante investir na continuidade/progressão da sua escolaridade. Tal situação teve repercussão direta no melhor aproveitamento e na vivência do espaço universitário, mas também na dimensão simbólica da permanência desse estudante, já que lhe possibilitaria concentrar-se apenas nas atividades acadêmicas. Há que se destacar que o fato de conseguir se manter somente estudando e vivenciando a universidade pode repercutir tanto na qualidade em termos formativos como no tempo de integralização do curso escolhido, contribuindo, assim, para que o estudante com o perfil analisado possa concluir sua graduação mais facilmente no tempo mínimo exigido.

Na mesma linha de discussão, outros autores, como Silva (2013), ponderam que as condições de permanência no ensino superior têm relação direta com o modo como os estudantes organizam e usam o tempo de que dispõem; ou seja, trabalhar e estudar ou só estudar pode ter repercussões no que diz respeito à participação dos estudantes em atividades como pesquisa, extensão, eventos científicos, entre outros. Isto posto, tal circunstância retrata uma nova relação estudo-trabalho com repercussões qualitativas quanto à constituição de seus percursos universitários. Nesses casos, o auxílio assistencial permite, mesmo que parcialmente, a subsistência material e minimiza a necessidade de apoio financeiro familiar. Isso significa dizer que, embora os rendimentos da atividade laborativa do estudante deixem de compor o orçamento familiar, em contrapartida o acesso aos recursos da assistência estudantil possibilita a desoneração relativa dessas famílias que, na sua maioria, não têm condições financeiras de arcar integralmente com os custos de manutenção dos estudantes na universidade - principalmente para aqueles que têm suas despesas aumentadas pelo fato de não poderem mais morar com a família, visto que o campus da universidade está localizado na região metropolitana da Baixada Santista, cuja distância 
inviabiliza o deslocamento diário até a residência familiar, localizada geralmente em outras regiões do estado.

Sabe-se que em boa parte dos casos o auxílio financeiro institucional não é suficiente para o custeio da totalidade das despesas materiais necessárias, principalmente as que envolvem o dispêndio com locação de imóveis, uma vez que o campus Baixada Santista está localizado em uma região metropolitana com alto custo de vida, muitas vezes maior que o da região de origem desses estudantes. Essa questão é recorrente e acaba por se refletir no cotidiano universitário desses estudantes.

\section{Bom desempenho acadêmico como estratégia de permanência material}

Observa-se, ainda, que a maioria dos partícipes da pesquisa expressou um grande comprometimento com o curso escolhido e com a sua formação e, por conseguinte, com o desempenho acadêmico. Um bom coeficiente de rendimentos constituiu-se, igualmente, como uma estratégia de permanência tanto simbólica quanto material, uma vez que, além de sinalizar um bom aproveitamento dos conteúdos acadêmicos, viabiliza, por outro lado, melhores condições de disputa e acesso às bolsas acadêmicas ${ }^{5}$. A Estudante de Nutrição (E6) relata ter-se utilizado deste expediente:

Querendo ou não, o coeficiente de rendimento é uma questão que eles (os docentes) avaliam também, né? Então, eu queria estar também entre os melhores da sala porque eu sabia que isso tinha algum peso quando a gente fosse procurar algum tipo de bolsa de iniciação científica ou extensão. E aí, eu fui me dedicando! E até agora eu estou satisfeita. (E6, Estudante de Nutrição, período integral, 25 anos).

Desse modo, ao mesmo tempo que cumpriam a carga horária de atividades complementares exigidas pelas matrizes curriculares dos seus cursos, os estudantes em questão agregaram pontos ao seu percurso formativo e, por fim, garantiram um adendo no que tange à possibilidade de recursos extraordinários para custeio de sua manutenção de ordem material, estratégia da mesma forma apontada pela Estudante de Serviço Social (E15):

[...] eu comecei a me dedicar. Aí que eu substituí meu salário que era um valor de uma bolsa (acadêmica), eu trabalhava como uma louca pra ganhar o valor da bolsa. Se for pra ganhar a mesma coisa, vamos fazer trabalho acadêmico que vai realmente responder ao que eu vim fazer e não tá fazendo sentido (fazendo referência à qualidade da formação extra sala de aula, diferencial da universidade pública em relação à universidade privada que cursava anteriormente). (E15, Estudante de Serviço Social, periodo vespertino, 23 anos).

Nesta perspectiva, ao se envolverem com atividades para-acadêmicas, os estudantes ficam mais tempo na universidade, e isso se torna um dispositivo para se apropriarem de "um mundo intelectual e institucionalmente mais complexo, compreender e fazer uso dos meandros que envolvem as regras e suas práticas, transitar num universo de relações mais amplo e múltiplo, em sentidos, valores e condutas" (TEIXEIRA, 2011, p. 48). Tal interpretação é também explicitada pela Estudante de Psicologia (E3) ao avaliar o alcance dos auxílios assistenciais em relação às perspectivas de pleitear bolsas acadêmicas e subsidiar sua permanência na universidade:

[...] Mas eu só consegui fazer um projeto bom do PIBIC $^{6}$ porque eu não precisei trabalhar quatro anos no bar até às duas da manhã. Então, foi uma estratégia que não é só minha. Eu construí estratégias direta e indiretamente e que também foram construídas aqui nessa relação, entende? E que acaba não sendo só bancária mesmo. Não tem como. Todas as vezes que eu pensava no

\footnotetext{
${ }^{5}$ Incluem bolsas vinculadas às atividades de extensão universitária, iniciação científica, programas de monitoria, programas de educação tutorial (PET) e programa institucional de incentivo à gestão (BIG/PRAE).

${ }^{6}$ O Programa Institucional de Bolsas de Iniciação Científica (PIBIC) visa apoiar a política de Iniciação Científica desenvolvida nas Instituições de Ensino e/ou Pesquisa, por meio da concessão de bolsas de Iniciação Científica (IC) a estudantes de graduação integrados na pesquisa científica. A cota de bolsas de IC é concedida diretamente às instituições, que são responsáveis pela seleção dos projetos dos pesquisadores orientadores interessados em participar do Programa. Os estudantes tornam-se bolsistas a partir da indicação dos orientadores.
} 
auxílio (assistencial) que eu recebia e explicava pra alguém, isso vinha muito na minha cabeça. É um auxílio para que eu permaneça. Então, tem a preocupação de que eu permaneça. Vamos permanecer e pensar como que faz. (E3, Estudante de Psicologia, periodo integral, 23 anos).

Desfrutar de uma bolsa acadêmica estimulou duplamente a permanência desses estudantes, visto que, ao mesmo tempo que isto reduz as preocupações de ordem material, também oportuniza a presença em jornada integral na universidade e, por conseguinte, uma melhor apropriação da cultura acadêmica. Essa condição, segundo Almeida (2006), faculta que os estudantes usufruam, de modo mais pleno, dos serviços e das possibilidades ofertadas pela universidade, aproximando-os da condição dos demais estudantes melhor posicionados em termos socioeconômicos.

A conquista de bolsas de monitoria, extensão universitária e/ou iniciação científica é fator relevante tanto em função das hierarquias estabelecidas entre os estudantes e da distinção que implicam no currículo, como também enquanto formação universitária. Além disso, os estudantes apropriam-se do espaço universitário, garantindo a si mesmos uma inserção ativa nesse novo ambiente, tornando-o familiar e diverso. Na perspectiva de Coulon (2008, p. 42), esses estudantes tornam-se membros, o que “designa o domínio natural do grupo ou da sua organização". Segundo Guesser (2003, p. 163), ser membro:

[...] não é apenas um ente que pertence a um determinado grupo, mas ao contrário, é um ente que compartilha a construção social daquele determinado grupo. Em outras palavras, é membro o indivíduo que domina a linguagem comum do grupo, que interage com os demais a partir de redes de significação estabelecidas nos processos interacionais, que compreende o mundo social em que está inserido sem grandes esforços racionais, mas apenas pela pertença natural de sua socialização.

Há, portanto, uma reconfiguração do espaço social da universidade pública com a inserção de estudantes das camadas populares e oriundos de trajetórias de vida distintas, diante não apenas da sua realidade socioeconômica, mas também no que se refere ao capital simbólico distinto dos grupos hegemônicos que representaram a clientela da universidade até então.

\section{A permanência simbólica}

Em que pesem as condições materiais de existência já pontuadas e que abrangem o eixo da permanência material, julga-se necessário ampliar a discussão para além da análise dos aspectos econômicos e financeiros que envolvem as trajetórias desse novo público universitário, numa perspectiva simbólica que contemple os sentidos, as interações, a apropriação do espaço universitário e a afiliação estudantil. Na perspectiva de Santos (2009, p. 159), permanecer simbolicamente requer "constância do indivíduo no ensino superior que permita a sua transformação, a partilha com seus pares e o pertencimento ao ambiente universitário". A permanência simbólica perpassa por uma efetiva integração a todos os aspectos da vida acadêmica, transcendendo a inclusão quantitativa. Todavia, essa distinção entre simbólico e material foi feita apenas para efeito de análise, uma vez que são dimensões que caminham juntas e estão interligadas.

No que tange à ótica da permanência simbólica, foram abordadas situações de preconceito vivenciadas, as diferenciações sutis a que foram submetidos esses estudantes no cotidiano universitário e as estratégias de superação de possíveis estigmas. Em contraste com a concepção de construção de uma permanência simbólica, notamos a existência de conteúdos explícitos e não explícitos que indicam situações de preconceito de diversas ordens, que foram vivenciadas e narradas por esses estudantes. Foram inúmeras as percepções de discriminação elencadas e que mereceram destaque na análise.

A Estudante de Serviço Social (E1) chama a atenção para as falas docentes acerca do REUNI e do novo público estudantil ingressante nas universidades públicas. Nas discussões que ocorreram no órgão colegiado do curso, no qual ela era representante discente, essa estudante capta a crítica à provável queda da qualidade do ensino, decorrente do processo de expansão e diversificação da forma de ingresso na universidade, que permitiu o ingresso de estudantes "inaptos e despreparados" ao percurso acadêmico: 
[...] Uma crítica, eu me lembro de falas sobre o REUNI, sabe?! Eu me lembro de falas de professoras. E aí, depois quando eu fui começando a entender o que era o REUNI, é que eu vi a crítica, onde estava. Quem tá tendo acesso à universidade pública, que já não vai... Como é?! Que não vai ser de excelência porque tem que atender à demanda que tá chegando e a demanda é de um bando de burro. E aí aquilo me deixou brava! A decepção começou dali. Quer dizer que eu faço parte dessa gama de bando de burros, que mal sabe escrever? Pera aí que eu vou mostrar que o bagulho é outro! (E1, Estudante de Serviço Social, periodo noturno, 51 anos).

Lembramos aqui as palavras de Coulon (2008, p. 68):

Dizer que 'eles não possuem nível' é como recolocar a questão da manifestação de seu habitus e, mais que isso, sua possibilidade de afiliação intelectual ao ensino superior. Esses estudantes sofrem uma ruptura que os distancia, um pouco mais, do que é requisitado no ensino superior, em termos de vocabulário, de conceitualização, de hábitos de leitura e escrita, de pensamento, enfim de um conjunto de operações intelectuais que caracteriza o trabalho acadêmico.

Foi possível perceber ainda, nos discursos, que há a expectativa em relação a um(a) estudante idealizado(a). Espera-se que o(a) novo(a) estudante chegue "pronto(a)", carregado(a) de atributos desejáveis ao meio acadêmico, o que leva os estudantes oriundos de grupos populares a se sentirem "fora do lugar, devedores eternos do ideal, que, diga-se de passagem, raras vezes é encontrado nos corredores das faculdades e institutos" (ALMEIDA, 2006, p. 9). Nota-se que esse modelo de estudante que ainda permanece no imaginário de parte da comunidade acadêmica é o que representa os estudantes oriundos de uma elite que ocupou exclusivamente, até pouco tempo, o espaço universitário público: brancos, do sexo masculino, com idade entre 18 e 20 anos, moradores das áreas urbanas, descendentes de imigrantes europeus, advindos de escola de ensino médio privada e que não teriam trabalhado até então.

Nesta linha, o que se mostrou inédito foi o relato de outra Estudante de Serviço Social (E15) - a única entre os entrevistados que ingressou por processo de transferência externa, e não pelo Sistema Único de Seleção Unificada (SISU). Ela traz em sua narrativa a vivência do estudante "transferido", que ingressa em um momento diverso no curso e com uma trajetória acadêmica anterior desigual. Este é o caso principalmente dos que são oriundos de instituições privadas de ensino superior. Ela afirma que a universidade ainda não sabe lidar com esse perfil de estudante e nem como recebê-lo. A estudante, ainda, menciona enfaticamente as situações de prejulgamento vivenciadas quando se identificava como estudante vinda por transferência externa: "as pessoas torciam o nariz pra mim".

Eu tinha a sensação que eu tinha passado por debaixo da porta, que é diferente, que é a diferença de quem vem de transferência. Quando você vem de transferência, as pessoas te olham com uma grande incerteza, com uma cara do tipo: é vamos ver! Então, isso é muito difícil, porque além de você acessar uma coisa que é sua por direito, você tem que ficar provando pras pessoas que você tem que tá aqui dentro. (E15, Estudante de Serviço Social, periodo vespertino, 23 anos).

Para a estudante, há, de modo tácito, uma mensagem que indica a visão de que o estudante transferido não se esforçou e entrou na universidade pública "por debaixo da porta". Portanto, o(a) estudante que ingressou por meio de outra modalidade que não o SISU tem uma condição simbólica desfavorável que coloca em suspeição o direito e a legitimidade de estudar em uma universidade pública.

A estudante (E15) destaca, ainda, a hierarquia de tratamento existente em relação às instituições de onde advieram os estudantes "transferidos". Para os que vinham de outras universidades federais ou até de instituições privadas, porém prestigiosas, havia uma respeitabilidade não oferecida aos que vinham de instituições particulares sem tradição, ou, como definiu a estudante (E15), das "uniesquinas", de modo que havia uma nítida diferenciação de tratamento a partir da origem institucional dos alunos.

Porque veio transferido da UFOP, da UFRJ, de outras federais. Até da PUC, por exemplo, que é particular, mas é PUC! E aí... Que sensacional! O corpo docente faz: vamos se apresentar, você é nova, tô vendo aqui. O seu nome tá sempre estranho na lista, aquela zona. Lógico que todo mundo vai saber que você não veio do SISU. Ah, você veio da onde? Todas falam. Aí você 
sempre tá na sala com os outros transferidos porque você tem que fazer o raio das mesmas matérias. Ah, eu vim da UFRJ, eu vim da UFOP, eu vim de não sei aonde... (as professoras dizem:) ah, que ótimo! Eu tenho um professor que é amigo lá... E você? Ah, eu vim da UNINOVE. Ah, legal... Então, o livro tal... Juro! Juro! Hoje eu já levo com uma dose de humor. Mas era assustador. Todas (as professoras) eram assim! Todas. "Ah, vamos ver, né?” Esse "vamos ver" é demais! Enfim, estamos aí, entre fracos e feridos. (E15, Estudante de Serviço Social, periodo vespertino, 23 anos).

Observa-se o predomínio de situação de preconceito velado, que não é explicitado diretamente e, muitas vezes, é naturalizado por meio de processos discursivos e culturais.

Questão semelhante foi expressa por outros estudantes que ingressaram pelo processo de reserva de vagas, leia-se cotas, ${ }^{6}$ e proferiram situações em que omitiam a sua condição de cotista. Tal comportamento buscava evitar possíveis cenários que suscitassem ações discriminatórias também associadas às discussões acerca da lógica do mérito e da sua relação com a suposta "qualidade" dos cursos de graduação - ou, ainda, como destaca Santos (2009), porque há no senso comum uma associação negativa entre estudante cotista e competência/desempenho, apesar de estudos e dados desmistificarem essa tese. Isso fica claro no silenciamento recorrente por parte dos estudantes cotistas em relação à identificação como tais, o que representa o sentimento de não pertencimento e de falta de legitimidade deles em relação ao espaço universitário. E6, ao ser perguntada acerca das suas expectativas em relação ao ingresso na universidade, menciona a preocupação em não acompanhar o curso principalmente pela sua condição de cotista:

[...] às vezes a gente sente que por ser aluno de cota, de escola pública... Às vezes, tem gente que tem um olhar preconceituoso. 'Ah, mas vai cair a qualidade do ensino'... E eu sempre tentei provar o contrário. Porque a gente sabe que pode ser que sim, mas não só porque o aluno veio de escola pública. (E6, Estudante de Nutrição, periodo integral, 25 anos).

[...] É até com a questão das cotas também. Eu nunca comentei com as pessoas, por exemplo, que eu entrei pela cota. Porque tem gente que não concorda. (E7, Estudante de Nutrição, periodo integral, 23 anos).

Ainda nesta mesma perspectiva, a Estudante de Ciências do Mar (E11) relatou episódio vivenciado em sala de aula, no qual uma professora mencionou ser contra a presença de estudantes cotistas na universidade, assim como era contrária à disponibilização de bolsas de fomento à pesquisa aos nordestinos, pois, em sua avaliação, esses alunos não sabiam como utilizar esses recursos. A professora justificava, ainda, que os pesquisadores das regiões Sul e Sudeste do País seriam mais "esforçados", estudavam mais e, por conseguinte, mereceriam maiores investimentos em relação aos das demais regiões da federação. Segundo relato da estudante, para a professora em questão, os cotistas estavam ocupando o lugar de pessoas que estudavam "de verdade".

Tal descrição só vem corroborar a avaliação feita por Santos (2009, p. 165): "ao fazer isso, estes educadores estereotipam seus alunos e os colocam em situação de inferioridade em relação aos seus colegas". Assim, a figura do professor nesse processo é duplamente central, uma vez que suas ações podem fragilizar ou colaborar positivamente para a permanência simbólica e também efetiva do estudante na universidade. Nessa linha, a autora ainda completa que:

O estigma é um elemento no rol dos obstáculos enfrentados pelos estudantes na sua tentativa de permanência simbólica. A autoestima de ser universitário é antagônica aos casos de exclusão e preconceito que estes jovens enfrentam em sua trajetória acadêmica. O próprio termo "cotista" é considerado, por muitos estudantes (ouvidos em nossa pesquisa) como pejorativo e repleto de signos excludentes (SANTOS, 2009, p. 16).

\footnotetext{
${ }^{6}$ Entre os anos de 2005 e 2012, a política de reserva de vagas instituída na UNIFESP aumentou em 10\% o número de vagas ofertadas nos seus cursos de graduação, as quais eram destinadas para estudantes egressos de escola pública e autodeclarados negros, pardos ou indígenas. 
Tais situações representam tensões e contrastes vivenciados no cotidiano universitário. Evidenciam os constrangimentos experimentados por esses estudantes na relação com os docentes e/ou com os demais colegas e também com o modelo de estudante que remete àquele vindo da elite e que ocupava os bancos das universidades públicas quase que exclusivamente - modelo este enraizado no imaginário de parte do professorado. É perceptível a sensibilidade dos entrevistados aos comentários pejorativos sobre a relação do ingresso de estudantes das camadas populares e a suposta queda da "qualidade" dos cursos das universidades públicas e sua relação direta com a lógica do mérito, uma vez que, para alguns educadores, esses estudantes teriam tirado a vaga de outrem supostamente mais preparado. Tal situação também é evidenciada em relação a estudantes transferidos de outras universidades, majoritariamente para os provenientes de instituições privadas menos prestigiosas.

A sensação de ter "entrado por baixo da porta" (expressão usada por um(a) estudante para se referir a como os estudantes são rotulados) representa o sentir-se como um intruso, como aquele que entra em algum lugar sem ter direito, sem ter sido convidado nem desejado (COULON, 2008). Dessa maneira, esse(a) estudante não é alçado(a) à condição de igual aos demais no sentido de direitos e, portanto, não é visto como digno(a) do benefício de estudar em uma universidade pública. Tal contexto configura, pois, uma situação de humilhação social que carrega em si repercussões do ponto de vista da lógica da exclusão, sob uma perspectiva de classe e no âmbito intersubjetivo do(a) estudante. O ingresso desses(as) estudantes na universidade pública, por si só, não resolve questões relacionadas à exclusão social, como destaca Rhodes (2014, p. 37):

[...] a desigualdade social e o preconceito não seriam, portanto, eliminados por via da ampliação de oportunidades ou de auxílio financeiro, pois a desigualdade também está caracterizada como uma ameaça permanente à existência: um lugar estereotipado, que pode impedir os sujeitos de se recriarem, transformarem-se.

Portanto, é possível dizer que a universidade ainda se organiza como um espaço hostil à diversidade e, por conseguinte, como não subsidiário à permanência simbólica dos novos grupos sociais que se dispõe a atender - ou, como também salienta Rhodes (2014), apesar dos discursos de democratização do ensino superior presentes nas leis e decretos, a exclusão no interior das universidades persiste sob a forma de ações de preconceito e discriminação. Embora tenha havido um progresso com a ampliação da possibilidade de acesso ao ensino superior público e a consequente redução da exclusão via restrição do acesso, há indícios de que a exclusão ainda se faz no interior do sistema de ensino superior público.

Entretanto, ao contrário do que se poderia imaginar, nota-se que as situações de preconceito vivenciadas se constituíram como força mobilizadora para que esses(as) estudantes desconstruíssem os prejulgamentos e as incertezas acerca da sua presença e permanência na universidade.

[...] Eu não tava acostumada com esse ritmo frenético de ficar o dia inteiro na faculdade. De ter que estudar muito! De você se dedicar ao máximo pra isso. Se você não se dedica, você não vai conseguir. Tem gente que tem mais facilidade. No meu caso, eu achava que precisava me dedicar o dobro do que eu já me dedicava. Porque eu não entendia nada do que os professores falavam. E a universidade é assim: "se vira meu filho!" (E2, Estudante de Terapia Ocupacional, periodo integral, 26 anos).

Foi preponderante a necessidade de provar bom desempenho acadêmico para ser reconhecido e aceito, o que se consubstanciou como uma estratégia de superação desses estudantes ao sentimento ou experiência de preconceito vivenciado pela condição de cotista e/ou com formação deficitária no que tange à educação pregressa.

Podemos notar, no relato de E2, que a linguagem usada, como se pode perceber por alguns termos ali presentes, demonstra um certo distanciamento da linguagem do meio universitário tradicional; isto é, o capital cultural, conceito elaborado por Bourdieu (2007), desses “novos" estudantes não é o mesmo detectado entre o perfil dos estudantes que comumente se encontraram e se encontram nesse espaço social. Isso significa mais uma questão relacionada à diferenciação, mas também um percalço para a adaptação desses estudantes no novo universo simbólico que representa a universidade pública. No 
entanto, conforme já havia observado Almeida (2006), embora a princípio não dispusessem do repertório cultural valorizado no ambiente acadêmico, esses estudantes, apesar das dificuldades para levar o curso adiante, acabaram por desenvolver disposições como determinação, dedicação e postura proativa, que impulsionaram suas trajetórias universitárias. Foi possível verificar que houve um investimento intenso por parte desse grupo em prol de um bom rendimento acadêmico e de uma formação profissional de qualidade, estratégia que lhe garantisse prestígio e legitimidade diante dos demais atores da comunidade acadêmica.

Estudos comparativos, como apontam Zimerman, Pinezi \& Silva (2015), sobre cotistas e não cotistas nas universidades públicas demonstram essa mesma situação em que inicialmente há grande dificuldade dos cotistas em acompanharem o ritmo de estudos, apresentando um rendimento mais baixo que os não cotistas. No entanto, geralmente entre um ano e dois, os estudantes cotistas tendem a ter o desempenho igualado aos não cotistas.

Ainda sob a ótica da permanência simbólica, chamou a atenção, em contraposição às situações de discriminação mencionadas, as relações e as interações que foram sendo desenhadas ao longo das trajetórias acadêmicas observadas. Acredita-se que estas também repercutiram no processo de afiliação e pertencimento dos estudantes que participaram da pesquisa. Nesse quesito, incluem-se as relações interpessoais entre discentes e docentes bem como o relacionamento ou envolvimento com atividades de ordem extracurricular que foram bastante mencionadas nas narrativas observadas.

No que tange à relação com o corpo docente, houve relato da Estudante de Terapia Ocupacional (E2), que destacou o papel desempenhado por duas docentes no início do curso, época durante a qual teve dificuldade com os conteúdos acadêmicos, precisando conciliar a graduação com a atividade laborativa. Essas docentes perceberam suas dificuldades, ofereceram incentivos e orientação para os estudos. Isso, na sua avaliação, foi essencial para a sua permanência na universidade em um período de incertezas e adversidades, principalmente porque a estudante, naquele momento, via-se obrigada a conciliar a atividade laborativa formal e as atividades acadêmicas. Outra Estudante de Serviço Social (E4) também menciona que seus professores foram cuidadosos no que se refere às dificuldades discentes em relação ao curso, mostrando-se acessíveis ao diálogo. Já a Estudante de Nutrição (E8) relata ter sido sempre incentivada por professores a continuar estudando e a desenvolver projetos de pesquisa, e isso contribuiu significativamente para o seu processo de afiliação estudantil. Na mesma linha, outra Estudante de Ciências do Mar (E10) relata ter-se sentido acolhida pelos docentes; e a universidade, para ela, fez-se um ambiente familiar, apesar de todas as limitações infraestruturais existentes no curso recémcriado.

[...] Os professores estão sempre te ajudando, qualquer um deles. Se você precisar de um equipamento, de um livro, eles vão sempre te ajudar. Não sei se porque começou esse curso pequeno, com pouca gente e aí foi crescendo. (E10, Estudante de Ciências do Mar, período vespertino, 26 anos).

O papel de orientação pedagógica e aconselhamento também desempenhado pelos docentes foi crucial frente às angústias e dúvidas em relação às possibilidades de atuação do bacharelado interdisciplinar, modalidade de curso nova e pouco conhecida fora do âmbito acadêmico.

Para autores como Tinto (1987 apud RHODES, 2014), o contato informal entre docentes e discentes, para além da mera formalidade do trabalho acadêmico e intelectual, contribui para o desenvolvimento educacional e, consequentemente, para o processo de afiliação e a permanência simbólica desses estudantes. Portes (2001, p. 208) aponta que "a ocupação dos diferentes espaços universitários, mesmo que ela se dê de forma lenta e gradual, à medida que o sujeito vai se sentindo mais 'adaptado' aparece como um elemento importante de sustentação da trajetória acadêmica e de formação da identidade dos nossos jovens". Nesse aspecto, foi possível observar que, dentre todos os participantes desta pesquisa, apenas um estudante relatou não ter tido inserção em projetos de pesquisa, extensão e/ou monitoria. Todos os demais construíram experiências extra sala de aula, e alguns também participaram de programas de mobilidade acadêmica. No que se refere às bolsas acadêmicas, excetuando-se o estudante mencionado, todos os demais entrevistados obtiveram bolsas de fomento para as atividades e/ou projetos nos quais atuaram ao longo da graduação. É possível, portanto, inferir que, contrariando 
as expectativas, esses estudantes foram capazes de responder às exigências acadêmicas, tendo sido reconhecidos por sua capacidade e empenho e, assim, constituído seus processos de afiliação estudantil.

Sobre isso, Machado (2011, p. 170) salienta que:

Em face aos discursos de democratização das instituições federais de ensino superior, que transformaram os cenários possíveis de enunciação, tanto dos estudantes quanto das demais pessoas que as constituem, ao mesmo tempo em que são fragmentados os modos hegemônicos de produção de identidades, pela própria diversidade que passa a compor essa instituição, são consolidados os desejos de consumir um mesmo modo de subjetivação, caracterizado pelo jovem intelectual/profissional, competitivo e que comprova seus méritos.

\section{CONSIDERAÇÕES FINAIS}

Ao refletir sobre o processo de reestruturação e expansão vivenciado pela Universidade Federal de São Paulo (UNIFESP) nos últimos dez anos, mais do que a perspectiva quantitativa, manifestada no incremento da oferta de vagas e cursos, este trabalho propôs um olhar para o novo público universitário que se fez presente com mais força no espaço acadêmico na última década e que, historicamente, esteve à margem do ensino superior, principalmente em uma instituição que tradicionalmente se constituiu junto aos quadros da elite.

Para além dos dados estatísticos de ingresso e permanência, deslocou-se aqui o olhar para a vida cotidiana desses(as) estudantes, para a relação com a atividade universitária, o financiamento da vida estudantil, a vida material e suas relações no plano simbólico no espaço universitário. Enfim, olhou-se para a trajetória acadêmica de um grupo de estudantes nas suas diversas interfaces.

Reforça-se que, dado o interesse de esta pesquisa ter como foco o processo de permanência na universidade pública de estudantes oriundos das camadas populares, as narrativas dos(as) estudantes aqui expostas apontam que sua trajetória ultrapassa a ruptura e superação das barreiras de ingresso, o que exigiu, por parte desses discentes, mecanismos de luta contra preconceitos e limitações presentes no ambiente universitário, como se apontou na análise.

Longe de pretender dar respostas acabadas para as questões levantadas, o trabalho pôde salientar "a emergência de processos desiguais produzidos mediante as distintas vivências e aproveitamento do curso de acordo com as classes sociais às quais os indivíduos pertencem" (ALMEIDA, 2006, p. 4), assim como as desigualdades sociais internas à universidade, trazendo a reflexão sobre as possibilidades de intervenção institucional, com vistas a dirimir ou mitigar esse panorama.

As narrativas dos(as) estudantes que puderam ser conhecidas mostram trajetórias construídas de forma exitosa, a despeito dos diversos obstáculos e percalços vivenciados não só do ponto de vista material, mas também simbólico. São estudantes que não carregavam, nos termos de Bourdieu (2014), o capital cultural valorizado e esperado no ambiente universitário, mas construíram uma capacidade de trabalho autônomo e, muitas vezes, solitário, a fim de cumprir as exigências acadêmicas cotidianas e caminhar em direção à conclusão de seus cursos.

A análise das entrevistas também mostra que os programas de Assistência Estudantil são fundamentais para proporcionar não só a permanência dos estudantes de camadas populares, ao oferecer subsídio para a satisfação das necessidades materiais imediatas, mas também são decisivos para o próprio ingresso desses candidatos. Além disso, esses estudantes, a estarem menos pressionados pela luta pela sobrevivência material, podem participar mais ativamente da vida universitária, o que, por sua vez, possibilita que eles se envolvam com projetos acadêmicos, construam sua identidade no meio acadêmico e possam desenvolver futuros empreendimentos em termos profissionais. Como se vê, as dimensões material e simbólica são justapostas.

No plano simbólico, pode-se ver, por meio das narrativas, que alunos cotistas e alunos transferidos, especialmente vindos de instituições privadas, expressam sua percepção sobre como são diferentemente tratados por professores e por colegas. A discriminação sofrida por esses estudantes expressa-se nas palavras de professores e colegas de sala, que classificam cotistas e alunos transferidos de instituições privadas como os responsáveis por uma suposta "queda da qualidade" no ensino. Por sua vez, essa discriminação tem impacto nas oportunidades de atividades extracurriculares, como as de 
pesquisa, nas quais esses alunos são frequentemente preteridos. Sentimento de não pertencimento e de falta de legitimidade aparecem de forma unânime nas narrativas desses estudantes estigmatizados.

Há que se ressaltar que o processo de permanência estudantil supera a garantia de condições mínimas oferecidas pelo poder público, que permitem a esses novos grupos apenas a frequência aos cursos. Tal premissa pôde ser corroborada por meio das entrevistas, algumas aqui analisadas. Em que pese a questão material objetiva como primeiro e relevante dificultador, a permanência trata-se de uma circunstância complexa, uma vez que as questões simbólicas e imateriais também são tão impeditivas dos percursos acadêmicos quanto as relativas à afiliação universitária. Destarte, a permanência efetiva ou a condição de membro universitário estão vinculadas às relações que o estudante poderá estabelecer dentro da universidade, conforme já apontava Coulon (2008).

Evocam-se, aqui, as proposições de Fraser (2002) acerca da justiça social, que também pode ser pensada, no cenário estudado, como inclusão para mitigar desigualdades sociais, neste caso pela via da educação. Fraser aponta que a justiça precisa ser vista de forma bifocal, isto é, por meio de duas lentes diferentes ao mesmo tempo, em que uma delas é a justiça referente à justa distribuição econômica e a outra é a que se vincula ao reconhecimento recíproco, em termos identitários e de cidadania, em espaços sociais. Concorda-se, como foi mostrado nesta análise, que, se essas duas lentes ou dimensões forem tomadas de forma estanque, não levam a uma compreensão plena do que seja justiça social e dos caminhos possíveis para alcançá-la.

Portanto, o reconhecimento e a valorização da diversidade, conjuntamente com a transformação da estrutura material ou distributiva, como propõe Fraser, podem possibilitar que espaços sociais, como a universidade, sejam mais plurais, inclusivos e transformadores. Permanência estudantil, nesta perspectiva, ultrapassa a dimensão da materialidade, e é "como o ato de continuar que permita não só a constância do indivíduo, mas também a possibilidade de existência com seus pares" (SANTOS, 2009, p. 4), exigindo, por extensão, no que tange às desigualdades, tanto redistribuição material quanto reconhecimento das diferenças.

\section{REFERÊNCIAS}

ALMEIDA, Wilson Mesquita. Desigualdades Educacionais. In: ZIMERMAN, Artur (Org.). Os 'Brasis'e suas Desigualdades. 1ª. ed. São Bernardo do Campo: Editora da UFABC, 2017, p.03-26.

ALMEIDA, Wilson Mesquita. Esforço contínuo: Estudantes com desvantagens socioeconômicas e educacionais na USP. Dissertação (Mestrado em Sociologia). São Paulo: Faculdade de Filosofia, Letras e Ciências Humanas da Universidade de São Paulo, 2006.

BOURDIEU, Pierre. Escritos da Educação. 9. ed. Petrópolis: Vozes, 2007.

BOURDIEU, Pierre; PASSERON, Jean Claude. Os Herdeiros: os estudantes e a cultura. Florianópolis: Editora da UFSC, 2014.

COULON, Alain. A Condição de Estudante: a entrada na vida universitária. Salvador: EDUFBA, 2008.

FRASER, Nancy. A justiça social na globalização: Redistribuição, reconhecimento e participação. Revista Crítica de Ciências Sociais, Coimbra, n. 63, p. 07-20, out. 2002.

GUESSER, Adauto Herculano. A etnometodologia e a análise da conversação e da fala. Revista Eletrônica dos Pós-Graduandos em Sociologia Política da UFSC, Florianópolis, v. 1, n. 1, p. 149-168, ago./dez. 2003. Disponível em: https://periodicos.ufsc.br/index.php/emtese. Acesso em: 10 nov. 2018. 
MACHADO, Jardel Pelissari. Entre Frágeis e Durões: Efeitos da política de assistência estudantil nos modos de subjetivação dos estudantes da Universidade Federal do Paraná. Dissertação (Mestrado em Psicologia). Curitiba: Faculdade de Psicologia da Universidade Federal do Paraná, 2011.

NIEROTKA, Rosileia L.; TREVISOL, Joviles V. Ações Afirmativas na Educação Superior: a experiência da Universidade Federal da Fronteira Sul. Chapecó: Editora UFFS, 2019.

PORTES, Écio Antônio. Trajetórias escolares e vida acadêmica do estudante pobre da UFMG: um estudo a partir de cinco casos. Tese (Doutorado em Educação). Belo Horizonte: Faculdade de Educação da Universidade Federal de Minas Gerais, 2001.

PORTES, Écio Antônio. Algumas dimensões culturais da trajetória de estudantes pobres no ensino superior público: o caso da UFMG. Revista Brasileira de Estudos Pedagógicos, Brasília, v. 87, n. 216, p. 220235, maio/ago. 2006.

RHODES, Carine de Almeida Arruda. Crônicas do Cotidiano Universitário: Um Estudo Sobre os Sentidos da Experiência da Graduação no Discurso de um Grupo de Acadêmicos da Universidade Federal do Paraná. Dissertação (Mestrado em Psicologia). Curitiba: Faculdade de Psicologia da Universidade Federal do Paraná, 2014.

SANTOS, Dyane Brito Reis. Para além das cotas: A permanência de estudantes negros no e Ensino Superior como política de Ação Afirmativa. Tese (Doutorado em Educação). Salvador: Faculdade de Educação da Universidade Federal da Bahia, 2009.

SILVA, Jailson de Souza e. Por que uns e não outros? Caminhada de jovens pobres para a universidade. Rio de Janeiro: Sete Letras, 2003.

SILVA, Paula Nascimento da. Do ensino básico ao superior. A ideologia como um dos obstáculos à democratização do acesso ao ensino superior público. Tese (Doutorado em Educação). São Paulo: Faculdade de Educação da Universidade de São Paulo, 2013.

TEIXEIRA, Ana Maria Freitas. Entre a Escola Pública e a Universidade: longa travessia para jovens de origem popular. In: SAMPAIO, Sônia Maria Rocha (Org.). Observatório da vida estudantil: primeiros estudos. Salvador: EDUFBA, 2011, p. 27-51.

ZIMERMAN, Artur; PINEZI, Ana Keila \& SILVA, Sidney Jard. Success or failure of affirmative action in higher education in Brazil? The UFABC case. Revista InterSciencePlace, v. 10, n. 2, abril/jun. 2015. Disponível em: http://www.interscienceplace.org/isp/index. php/isp/article/view/344/318. Acesso em: 10 nov. 2018

Submetido: $24 / 07 / 2019$

Aprovado: $25 / 03 / 2021$ 